\title{
Quantitative Assessment of the Dynamics of the Economic Development of Socioeconomic Systems Based on the MDD Method
}

\author{
Romualdas Ginevicius $^{1}$, Dainora Gedvilaite ${ }^{1}$, Andrius Stasiukynas ${ }^{2}$, Jolita Sliogeriene ${ }^{1}$ \\ ${ }^{1}$ Vilnius Gediminas Technical University \\ Sauletekio al. 11, LT-10223 Vilnius, Lithuania \\ E-mail.Romualdas.ginevicius@vgtu.lt; dainora.gedvilaite@vgtu.lt; jolita.sliogeriene@vgtu.lt \\ ${ }^{2}$ Kazimieras Simonavicius University \\ Dariaus ir Gireno st. 21, LT-02189 Vilnius, Lithuania \\ E-mail.andrius@snowarena.lt \\ cross $^{\text {ref }}$ http://dx.doi.org/10.5755/j01.ee.29.3.20444
}

\begin{abstract}
An inherent characteristic of socioeconomic systems (SES) is their development, which is a prerequisite for their existence. Analysing the development, as well as comparing the subjects at a variety of levels (companies, countries, regions, etc.) for other purposes requires the development process to be measured in a quantitative manner. The development process is characterised by its dynamics, which in turn may be measured using two indicators: the intensity of the development; and its consistency over the reference period. The former measurement is represented as a ratio between the development values at the beginning of the period and those at the end, while the consistency of the SES economic development will be demonstrated as a ratio of the length of the reference period to the sum of the lengths of the trajectories representing the development over individual time periods. The calculations of the economic development of a number of countries carried out through this research have confirmed that the proposed methodology is appropriate. The methodology has been named, with certain qualifications, the MDDSS (Measuring of the Dynamic of the Development of a Socioeconomic System).
\end{abstract}

Keywords: Socioeconomic Systems; Economic Development; Dynamics of Development; Multicriteria Methods; System Theory.

\section{Introduction}

Processes and phenomena may vary greatly according to the nature of a number of qualities - physical, chemical, social, etc. Socioeconomic qualities, which combine active and inactive elements in an organic manner, take a very special place among them. The active elements in these processes are the people; whereas the inactive ones include materials and technical resources. Such phenomena share the following characteristics: intricacy and complexity. Thus, in reality, they are manifest in many different aspects. In the aggregate, they also meet three fundamental conditions: entirety, interaction and structuring. The first condition is fulfilled because the above aspects represent one and the same phenomenon or process in question; thus, they outline the boundaries of the system. The second condition is met because these aspects, which can be perceived as elements of the system, are inter-linked. The absence of such links would render the targeted development of a process or a phenomenon impossible. The fulfilment of the third condition presupposes interactions between the elements, because for the purpose of achieving a common objective in the system they are positioned in terms of each other in a certain order, i.e. they form a structure (Strakova, 2015; Armas-Cruz et al., 2017; Hashem-Nazari et al., 2017; Hodinkova \& Sadovsky, 2016; Wegner et al., 2017; Dobrovic \& Timkova, 2017).

Therefore, a socioeconomic process or a phenomenon may be perceived as a socioeconomic system (SES). Such systems, in addition to their intricacy and complexity, have one more fundamental characteristic, which is that they are dynamic. They are in constant motion and in continual development. Motion (development) is their inherent characteristic and it is a prerequisite for their existence. This is clearly illustrated with the relatively simple example of a man/bicycle system. When the bicycle stops, the man falls to the ground alongside it. The system collapses.

The need for the development of socioeconomic systems also arises due to the fact that they are open; thus, they are constantly exposed to the changing environment. To survive, the system may adapt to this external situation only by changing its own parameters accordingly, and this is only possible through the course of development (motion). Furthermore, to be able to successfully function in a dynamic environment, the changes of the SES must happen faster than the changes taking place in the surrounding environment. Thus, a fundamental prerequisite for the existence of the SES is its ongoing development (ongoing motion). Therefore, from both the scientific and the practical points of view, it is important to examine the development process of a socioeconomic system in a comprehensive manner and to look for the conditions affecting its success. This is evident from the fact that today, scholars, practitioners and even politicians do not talk about the development in itself, which is taken for granted, but rather speak about what that development should be like: 
intense, stable, sustainable, and so on. (Ciegis et al., 2010). The aim of the article is the quantitative assessment of the dynamics of the development of a socioeconomic system, which combines the uniformity and intensity of development.

\section{Options for Presenting the Development of Socioeconomic Systems}

In order to make a quantitative assessment of the development of a socioeconomic system, it is necessary to decide in what way it may be presented. In some cases, the proposed indicator is the gross domestic product (GDP) per capita. It is then considered that any of variations of the GDP represent the success and the development level of the reference SES (Chansara, 2013; Ciegis et al., 2010; Bolcazova \& Kološta, 2015; Babu \& Datta, 2015; Mally, 2018; Docekalova, 2015; Tvaronaviciene \& Razminiene, 2017).

A multicriteria assessment of the development of a socioeconomic system is also a widely used approach. These methods have recently become increasingly popular in terms of measuring social and economic phenomena (Ginevicius et al., 2015, 2016; Mardani et al., 2015; Zhou et al., 2007; Zavadskas et al., 2014; Strezov et al., 2017; Touceda et al., 2018).

However, the best known and the most frequently used approach is the SAW method (Simple Additive Weighting) (Hwang, Yoon 1981). The $S_{j}$ criterion of this method represents the idea behind a multicriteria assessment, i.e. the values of the indicators are combined with the indicator weights into a single measurement:

$$
K_{j}=\sum_{i=1}^{m} w_{i} \tilde{r}_{i}
$$

where $K_{j}-$ the criterion of the SAW method; $w_{i}-$ the weight of the $\mathrm{i}^{\text {th }}$ indicator; $\tilde{r}-$ the normalised value of the $\mathrm{i}^{\text {th }}$ indicator.

Before making any calculations using formula (1), the direction of the indicator variations has to be harmonised, i.e. all indicators need to be turned into maximising or minimising ones; and in addition, they have to be made dimensionless, i.e. normalised.

The conversion of the minimising indicators into the maximising ones may be performed in the following manner (Hwang \& Yoon, 1981):

$$
\bar{r}_{i j}=\frac{\min _{j} r_{i j}}{r_{i j}}
$$

Meanwhile, the conversion of the maximising values into the minimising ones shall be carried out in the following way (Hwang \& Yoon, 1981):

$$
\bar{r}_{i j}=\frac{r_{i j}}{\max _{j} r_{i j}}
$$

Normalisation shall be performed as follows (Zavadskas et al., 2014):

$$
\tilde{r}_{i j}=\frac{\bar{r}_{i j}}{\sum_{j=1}^{n} \bar{r}_{i j}}
$$

where $\mathrm{n}$ - the number of alternatives to the phenomenon (process) in question.

Multicriteria methods are generally used for comparing the economic development of different countries. The basis for such an assessment lies in a system of indicators. Their number must be neither too big nor too small, i.e. so as to represent all the fundamental characteristics of the phenomenon (process) in question, on the one hand; while avoiding the inclusion of indicators representing secondary aspects, on the other hand. Any failure to comply with this may lead to an inadequate outcome of a multicriteria assessment or a reduced accuracy of the assessment because of the excessively broad scope of the evaluation. An analysis of the research studies shows that the systems of indicators can be very different from one another. Some recur in almost all research, whereas others differ in various studies. For the analysis of ten countries in southern Europe, Germany and Russia, the measurement of their economic development relied on 9 indicators (GDP, unemployment, inflation, exports, industrial growth, the Gini coefficient, etc.) (Radonovich \& Lior 2017). All indicators were assumed to carry identical weights. What is more, 10 indicators, including the GDP per capita, were used for examining the economic development of the Chinese Suihua region (Jis et al., 2007). Nonetheless, in the assessment of development in the European Union countries 12 indicators were used, including the GDP per capita (Bolcazova \& Kološta, 2015). S. Chursan (2013) carried out an evaluation of the sustainable development in a region of Thailand. In his indicator system, he included the following 3 indicators: GDP per capita, $\mathrm{CO}_{2}$ emissions and energy consumption. An assessment of economic development on the basis of three indicators was also carried out by Babu and Datta. They combined the following 3 indicators into a single summarised measurement: GDP per capita, economic growth rates and economic structure (Babu \& Datta, 2015). In addition, developing countries (Peru, Mauritius, the Philippines, Bangladesh, Ghana, India, etc.) were subjected to their scrutiny.

Using multicriteria methods, the sustainable development of Italy and its regions was evaluated. This model comprised 18 indicators (Boggia \& Cortina 2010). These methods have also been used for measuring the sustainable development of urban areas (Zinatiradet et al., 2017). In this case, the system of indicators included 44 indicators. Their weights were determined on the basis of Shannon Entropy.

It is evident from formula (1) that the basis of the multicriteria assessment consists of a data matrix $R=\left\|r_{i j}\right\|$ of the indicators $R_{i}(\mathrm{i}=1,2, \ldots, \mathrm{m})$ outlining the alternatives $A_{j}(j=1,2, \ldots, n)$ to be compared and a vector of the indicator weights $\Omega=\left\|w_{i}\right\|$. Thus, the system of indicators applicable to all alternatives must consist of identical indicators in terms of their number and composition.

The above overview of the evaluation of the development of a variety of phenomena and processes based 
on multicriteria methods has demonstrated that, while the authors invoke different indicators, their number also ranges from just a few to a few dozen. This leads to the conclusion that the findings of individual studies may not be compared with the outcomes of others. Another difficulty that researchers face when developing an appropriate system of indicators for the multicriteria assessment is the ability to obtain unbiased raw data. This factor may be one of the primary causes of the significant number and variety of indicators being included in the system.
On the other hand, almost all the authors include the GDP per capita as a key element of their system of indicators pertinent to the SES economic development. Therefore, in order to assess the economic development of a country and its dynamics, this study will be based on this particular indicator. The fact that this results in a sufficiently visual representation of the dynamics of the development is shown in Table 1 and Figure 1.

Table 1

GDP per Capita, EUR, in Certain European Countries (Source: Compiled by the Authors Based on Eurostat Data)

\begin{tabular}{|c|c|c|c|c|c|c|c|c|c|c|}
\hline \multirow[t]{2}{*}{ Country } & \multicolumn{10}{|c|}{ Year } \\
\hline & 2007 & 2008 & 2009 & 2010 & 2011 & 2012 & 2013 & 2014 & 2015 & 2016 \\
\hline 12 EU countries & 29.2 & 29.7 & 28.6 & 29.3 & 29.9 & 30.0 & 30.2 & 30.8 & 31.7 & 32.4 \\
\hline Lithuania & 13.4 & 15.5 & 14.2 & 14.9 & 15.6 & 15.4 & 15.0 & 14.9 & 16.0 & 16.7 \\
\hline Greece & 21.1 & 21.8 & 21.4 & 20.3 & 18.6 & 17.3 & 16.5 & 16.4 & 16.3 & 16.2 \\
\hline Italy & 27.4 & 27.6 & 26.4 & 26.8 & 27.3 & 26.7 & 26.5 & 26.7 & 27.2 & 27.7 \\
\hline Switzerland & 46.2 & 49.3 & 50.2 & 56.1 & 63.7 & 65.0 & 64.1 & 65.3 & 73.9 & 72.2 \\
\hline
\end{tabular}

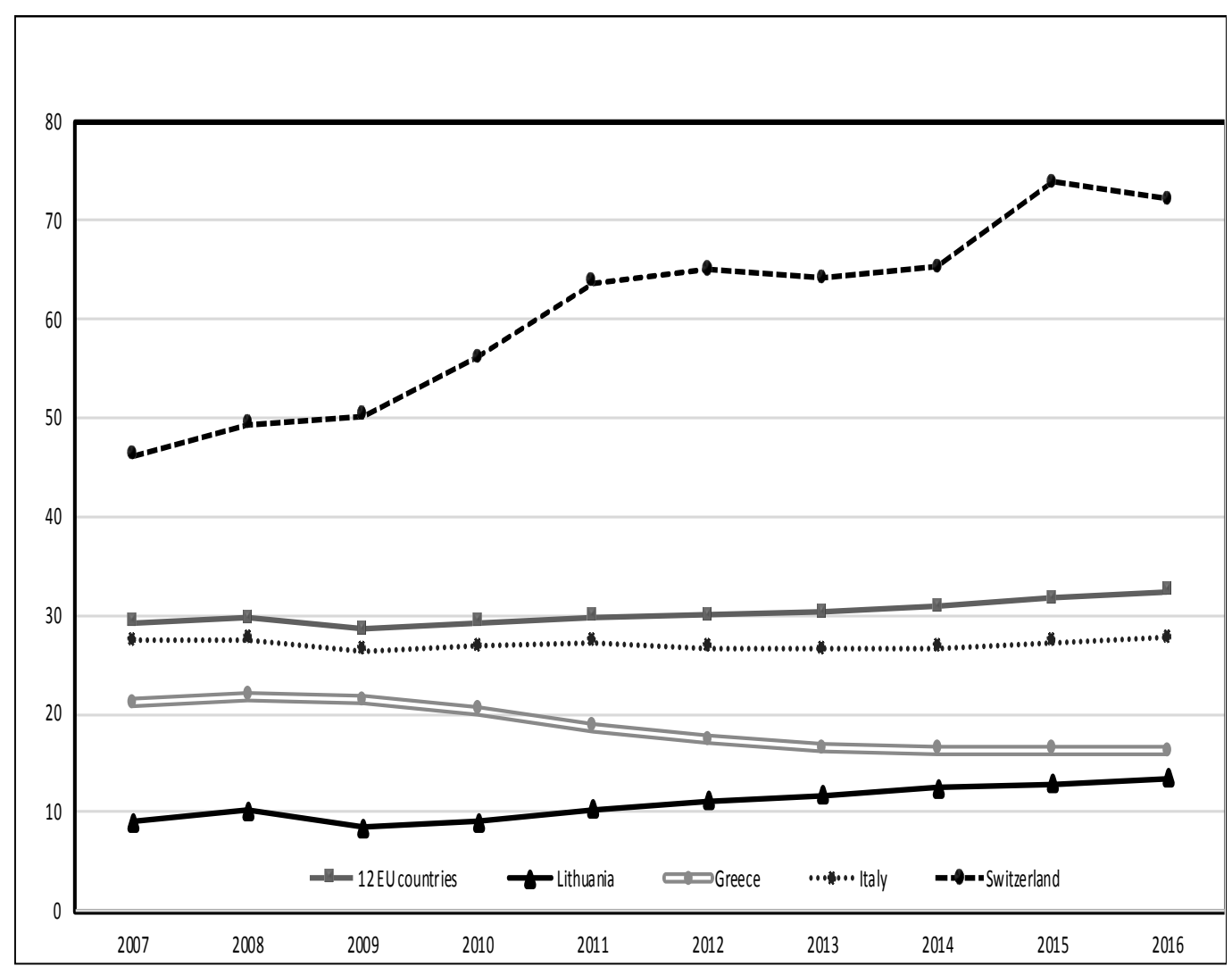

Figure 1. GDP per Capita (EUR) in Certain European Countries (Source: Compiled by the Authors Based on Eurostat Data)

\section{Proposed Methodology for a Quantitative Assessment of the Dynamics of the Economic Development of Socioeconomic Systems}

Before starting to speak about the assessment of the dynamics of the SES economic development, one needs to have a clear understanding of what is included in this term, i.e. what development parameters it represents. Dictionaries provide the following definition: dynamics - changes or the development of a certain phenomenon, or evolution of something. They maintain that a dynamic process is a characteristic of fast and clear development (Lithuanian dictionary). The following synonyms can therefore be suggested: sustainable, stable, ongoing, consistent, etc.

It is apparent from Figure 1 that the development status of a country can be described using three parameters: the intensity, the consistency and the length of the reference period. The first two parameters are variable, and they are different for each and every SES. This fact leads to two different possible scenarios in the dynamics of the SES of economic development (Figure 2). 
Romualdas Ginevicius, Dainora Gedvilaite, Andrius Stasiukynas, Jolita Sliogeriene. Quantitative Assessment of the...

\begin{tabular}{|c|c|c|c|}
\hline \multirow{2}{*}{\multicolumn{2}{|c|}{ Development }} & \multicolumn{2}{|c|}{ Intensity of the development } \\
\hline & & intense & non-intense \\
\hline \multirow{2}{*}{ 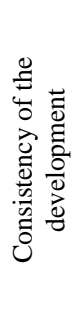 } & 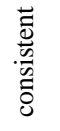 & intense and consistent & non-intense, but consistent \\
\hline & 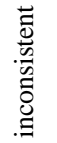 & intense, but inconsistent & $\begin{array}{l}\text { non-intense and } \\
\text { inconsistent }\end{array}$ \\
\hline
\end{tabular}

Figure 2. Possible Scenarios in the Dynamics of the Development of a Socioeconomic System (Source: Developed by the Authors)

In Figure 1, the dependence between the intensity and consistency of the development is highlighted. As the intensity increases, the consistency of the development decreases. Hence, in order to obtain an adequate picture of the consistency of the development, the value of its indicator should not be affected by the intensity of the development. The intensity has to be integrated, in an appropriate manner, into the indicator in order for the dynamics of the development to be developed. All of the above leads to the conclusion that for the consistency of the development, the indicator should rely on two parameters: the fluctuations of the development and the span of the reference period. The latter is the same for all the SES to be compared.

Therefore, the following structure of the indicator for the dynamics of the SES development becomes apparent (Figure 3).

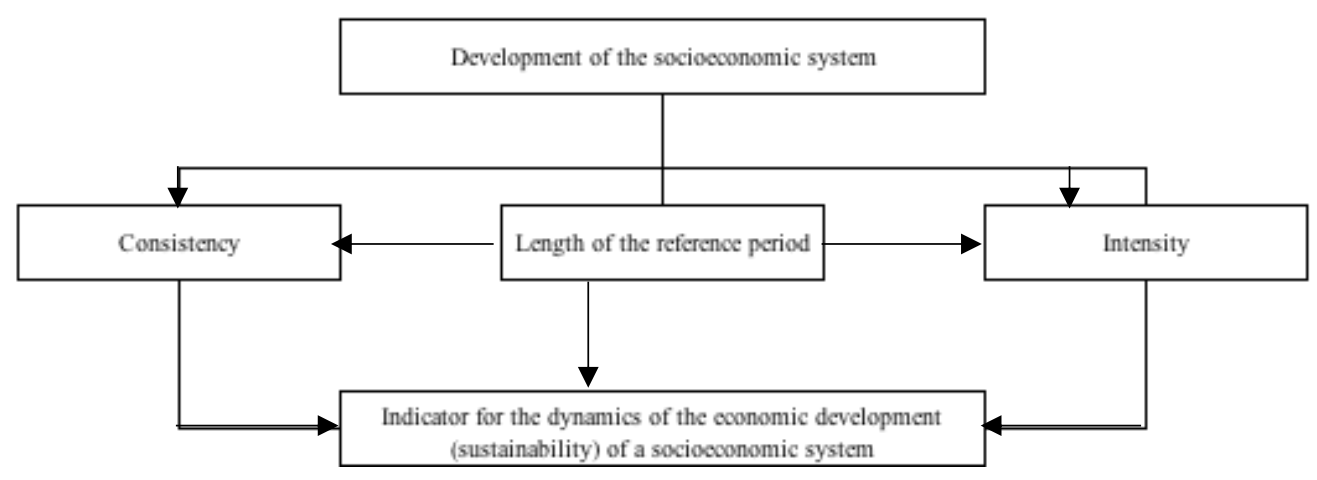

Figure 3. Structure of the Indicator for the Dynamics of the Development (Sustainability) of a Socioeconomic System

The situation of the consistency of the SES development can be pictured separately from the intensity thereof only after an assessment of its fluctuations during the individual time periods of the reference period. They may be represented in two ways: variation, i.e. a ratio between the development values of two adjacent time periods in the reference period (for example, years); or the difference between these values. The answer as to which of these better represents the development changes lies in a specific example (Table 2).

Table 2

Development of Switzerland and Italy in 2014-2015, GDP per Capita, EUR (Source: Compiled by the Authors based on Eurostat Data)

\begin{tabular}{|c|c|c|c|c|c|c|}
\hline Country & $\begin{array}{l}\text { Development } \\
\text { performance in } \\
2014\end{array}$ & $\begin{array}{l}\text { Development } \\
\text { performance in } \\
2015\end{array}$ & $\begin{array}{c}\text { Ratio between the } \\
\text { development } \\
\text { values } \\
\left(\frac{2015 \mathrm{~m} .}{2014 \mathrm{~m} .}\right)\end{array}$ & $\begin{array}{l}\text { Difference } \\
\text { between the } \\
\text { development } \\
\text { values } \\
(2015-2014)\end{array}$ & $\begin{array}{l}\text { Ratio between the } \\
\text { relationships }\end{array}$ & $\begin{array}{l}\text { Ratio } \\
\text { between the } \\
\text { differences }\end{array}$ \\
\hline Switzerland & 65.3 & 73.9 & 1.13 & 8.6 & \multirow[t]{2}{*}{1.11} & \multirow[t]{2}{*}{17.2} \\
\hline Italy & 26.7 & 27.2 & 1.02 & 0.5 & & \\
\hline
\end{tabular}

It is clearly visible from Table 2 that the status of the development is represented significantly more accurately by the differences between the development values of the adjacent time periods.
If one takes this measure (a difference between the development values) as the basis for the indicator that is being sought, then instead of the upward curves pictured in Figure 1 one will end up with a non-upward curve (see Figure 4). 


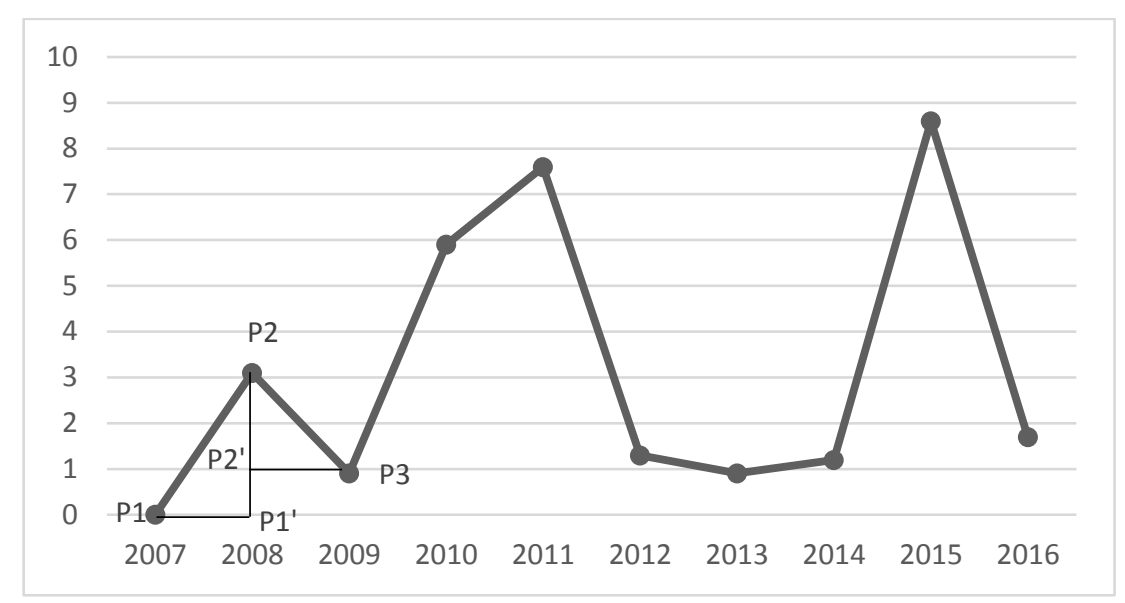

Figure 4. Consistency of Swiss Economic Development in 2007-2016 (Source: Compiled by the Author based on Eurostat Data)

On the basis of Figure 4, it is possible to determine the size of the trajectory that depicts the actual development of every time period that is part of the reference period. To this end, let us depict the trajectory as the hypotenuse of a rightangled triangle (see Figure 5).
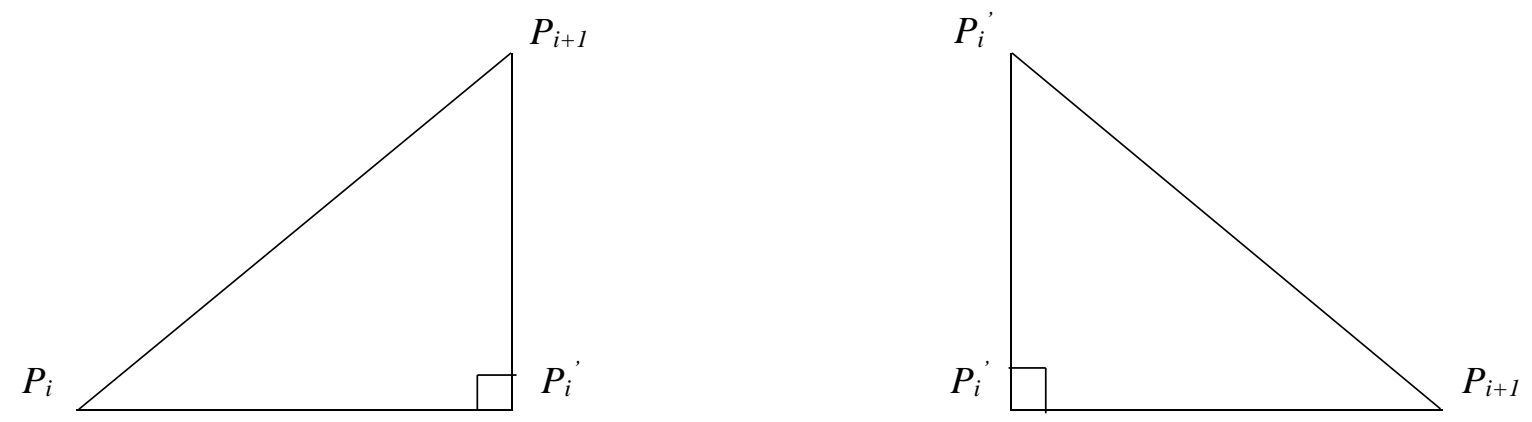

Figure 5. Representation of the Actual Trajectory of the SES Economic Development of the Reference Period Depicted through RightAngled Triangles $\left(P_{i}-\right.$ the Value of the Economic Development at the Start of the $\mathrm{i}^{\text {th }}$ Time Period; $P_{i+1}-$ the Value of the Economic Development at the end of the $\mathrm{i}^{\text {th }}$ Time Period; $P_{i}=P_{i}^{\prime}$ )

Figure 5 shows that the $P_{i} P_{i+1}$ part of the $P_{i} P_{i}^{\prime} P_{i+1}$ triangle represents the scope of the economic development during the $\mathrm{i}^{\text {th }}$ time period. Its value shall be determined in the following manner:

$$
\Delta P_{i}=P_{i+1}-P_{i}
$$

where $\Delta P_{i}-$ the scope of the economic development during the $\mathrm{i}^{\text {th }}$ time period part of the reference period.

It is also evident from Figure 5 that the other section $P_{i}$ $P_{i}^{\prime}$ of the $P_{i} P_{i}^{\prime} P_{i+1}$ triangle equals the length of the $\mathrm{i}^{\text {th }}$ time period part of the reference period. The total length of the reference period $\mathrm{T}$ will equal a sum of the lengths of the time period parts during this period:

$$
T=\sum_{i=1}^{m} t_{i}
$$

where $t_{i}$ - the length of the $\mathrm{i}^{\text {th }}$ time period part of the reference period.

The value of the $i^{\text {th }}$ time period part of the reference period shall be obtained by dividing the length of this period $\mathrm{T}$ by the number of time periods. Figure 1 shows that $\mathrm{m}=\mathrm{n}$ -1 .

$$
t_{i}=\frac{T}{m}
$$

Figure 1 also demonstrates that $\mathrm{T}=\mathrm{n}-1$, hence

$$
t_{i}=\frac{n-1}{n-1}=1
$$

Therefore, the $P_{i} P_{i}$ 'section of the $P_{i} P_{i}{ }^{\prime} P_{i+1}$ triangle shall equal 1 for all time periods because $t_{i}=t_{i+l}$.

The main idea behind the proposed quantitative assessment of the dynamics of the SES economic development is the ratio of the measurement representing the total length of the reference period to the total length of the actual development trajectory.

$$
D_{T}=\frac{\sum_{\mathrm{i}=1}^{\mathrm{m}} \mathrm{t}_{\mathrm{i}}}{\sum_{\mathrm{i}=1}^{\mathrm{m}} \mathrm{P}_{\mathrm{i}} \mathrm{P}_{\mathrm{i}+1}}=\frac{\mathrm{T}}{\mathrm{P}}
$$

where $\mathrm{D}_{\mathrm{T}}-$ the indicator of the consistency of the SES economic development; $\mathrm{P}-$ the total length of the actual trajectory of the SES economic development.

The length of the $P_{i} P_{i+1}$ hypotenuse of the $P_{i} P_{i}{ }^{\prime} P_{i+1}$ will mark $-1_{i}, P_{i} P_{i+1}-\widetilde{l}_{l}$. Based on formulas 7 and 8 , we find that the length $P_{i}{ }^{\prime}$ is equal to ti. Triangle shall be determined in accordance with the right-angled triangle rule: 
Romualdas Ginevicius, Dainora Gedvilaite, Andrius Stasiukynas, Jolita Sliogeriene. Quantitative Assessment of the...

$$
l_{i}^{2}=t_{i}^{2}+l_{i}^{2}
$$

hence

$$
l_{i}=\sqrt{t_{i}^{2}+\widetilde{l_{l}^{2}}}
$$

Whereas $P_{i} P_{i}^{\prime}=t_{i}=1$, then

$$
l_{i}=\sqrt{1+\widetilde{l_{l}^{2}}}
$$

Thereby, the formula for the quantitative assessment of the dynamics of the SES economic development (14) is as follows:

$$
D_{T}=\frac{n-1}{\sum_{i=1}^{n-1} \sqrt{1+P^{2}}}
$$

Formula (13) was used as the basis for establishing the consistency of the economic development in the reference countries (Table 3).

Table 3

Consistency of the Economic Development in the Reference Countries in 2016-2017

\begin{tabular}{|l|r|}
\hline \multicolumn{1}{|c|}{ Country } & \multicolumn{1}{c|}{ Value of the development consistency indicator $\boldsymbol{D}_{\boldsymbol{D}}$} \\
\hline 12 EU countries & 0.84 \\
\hline Greece & -0.76 \\
\hline Italy & 0.88 \\
\hline Lithuania & 0.70 \\
\hline Switzerland & \\
\hline
\end{tabular}

In order to assess the sustainability of development, the consistency of the development needs to be combined with its intensity (Figure 3). This can be done in a variety of ways, i.e. by using the product of the values, the geometric mean, and taking into consideration their weight on the overall development process.

The manner in which the consistency of the SES development is integrated with its intensity depends on the objective of the analysis. It may take two shapes: either with an analysis of the dynamics of the economic development in a country in isolation; or a comparison of the reference countries with one another.

$$
\begin{aligned}
& D_{M}=\frac{Q_{f}}{Q_{b}} \\
& P_{j}=\frac{Q_{f j}}{Q_{b}^{\min }}
\end{aligned}
$$

\begin{tabular}{|c|c|c|c|c|c|c|c|c|c|}
\hline \multirow{4}{*}{ Country } & \multicolumn{9}{|c|}{ Value of the integrated indicator for the dynamics of the development in the country } \\
\hline & \multicolumn{3}{|c|}{ individual countries } & \multicolumn{6}{|c|}{ comparison of the countries } \\
\hline & \multirow{2}{*}{$\begin{array}{l}\text { consistency of } \\
\text { the } \\
\text { development } \\
\left(\mathrm{D}_{\mathrm{T}}\right)\end{array}$} & \multirow{2}{*}{$\begin{array}{c}\text { intensity of the } \\
\text { development }\left(\mathrm{D}_{\mathrm{M}}\right)\end{array}$} & \multirow[t]{2}{*}{$\begin{array}{c}\text { integral } \\
\text { indicator }\left(\mathrm{D}_{\mathrm{D}}\right)\end{array}$} & \multicolumn{2}{|c|}{$\begin{array}{c}\text { consistency of the } \\
\text { development }\end{array}$} & \multicolumn{2}{|c|}{$\begin{array}{c}\text { intensity of the } \\
\text { development }\end{array}$} & \multicolumn{2}{|c|}{$\begin{array}{l}\text { integral indicator } \\
\left(D_{D j}\right)\end{array}$} \\
\hline & & & & value & ranking & value & ranking & value & ranking \\
\hline $\begin{array}{ll}12 & \mathrm{EU} \\
\text { countries } & \\
\end{array}$ & 0.84 & 1.11 & 0.93 & 0.84 & 2 & 3.6 & 2 & 3.02 & 2 \\
\hline Greece & -0.76 & -0.77 & -0.59 & -0.76 & 5 & -1.8 & 5 & -1.367 & 5 \\
\hline Lithuania & 0.70 & 1.50 & 1.05 & 0.70 & 3 & 1.5 & 4 & 1.05 & 4 \\
\hline Switzerland & 0.29 & 1.56 & 0.45 & 0.29 & 4 & 8.0 & 1 & 2.32 & 1 \\
\hline
\end{tabular}

Values of the Integrated Indicators of the Dynamics of Development in the Reference Countries $D_{D}$ and $D_{D j}$

In principle, the view will change if the indicators of the development consistency and intensity are weighted. In this case, the integral indicator for the dynamics of the development may be determined as follows:

$$
\begin{aligned}
& \widetilde{D_{D}}=w_{t} D_{t}+w_{m} D_{m j} \\
& \widetilde{D_{D_{j}}}=w_{t} D_{t j}+w_{m} D_{m j}
\end{aligned}
$$

where $\widetilde{D}_{D}$ - the indicator of the integrated assessment of the SES economic development where the analysis is concerned about the development of a country in isolation; where $D_{M}$ - the intensity of the economic development of a country over the reference period; $Q_{f}\left(Q_{f j}\right)$ - the value of the economic development of a country (the $\mathrm{j}^{\text {th }}$ country) at the end of the reference period; $Q_{b}\left(Q_{b j}\right)$ - the value of the economic development of a country (the $j^{\text {th }}$ country) at the start of the reference period; $Q_{b}^{\text {min }}$ - the value of the development of one of the countries, to be compared with the lowest value, at the start of the reference period.

The integral indicator for the dynamics of the SES development $D_{D}$ shall be determined as follows:

$$
\begin{aligned}
& D_{D}=D_{T} \times D_{M} \\
& D_{D j}=D_{T j} \times D_{M}
\end{aligned}
$$

Table 4 provides for the $\mathrm{D}_{\mathrm{D}}$ and $D_{D j}$ values of the reference countries.

Table 4
$\widetilde{D}_{D j}$ - the indicator of the integrated assessment of the SES economic development when the countries are compared with one another; $w_{t}$ - the significance of the consistency of the economic development to the dynamics of the development; $w_{m}-$ the significance of the intensity of the economic development to the dynamics of the development.

It is generally accepted, with qualifications, that in certain cases $w_{t}=0.4$, and $w_{m}=0.6$; whereas in other cases, they equal 0.3 and 0.7 , respectively. The results of the calculations are presented in Table 5. 
Values of the Indicators for the Dynamics of the Development in the Reference Countries on the basis of the Weighted Indicators

\begin{tabular}{|c|c|c|c|c|c|c|c|c|}
\hline \multirow{6}{*}{ Country } & \multicolumn{8}{|c|}{ Weights of the indicators } \\
\hline & \multicolumn{4}{|c|}{ Case 1} & \multicolumn{4}{|c|}{ Case 2} \\
\hline & \multicolumn{2}{|c|}{ within the country } & \multicolumn{2}{|c|}{ comparison of the countries } & \multicolumn{2}{|c|}{ within the country } & \multicolumn{2}{|c|}{ comparison of the countries } \\
\hline & consistency & intensity & consistency & intensity & consistency & intensity & consistency & intensity \\
\hline & \multirow{2}{*}{0.4} & \multirow{2}{*}{0.6} & 0.4 & 0.6 & \multirow{2}{*}{0.3} & \multirow{2}{*}{0.7} & 0.3 & 0.7 \\
\hline & & & value & ranking & & & value & ranking \\
\hline $\begin{array}{l}12 \text { EU } \\
\text { countries }\end{array}$ & \multicolumn{2}{|c|}{1.0} & 2.50 & 2 & \multicolumn{2}{|c|}{1.03} & 2.77 & 2 \\
\hline Greece & \multicolumn{2}{|c|}{-0.766} & -0.43 & 5 & \multicolumn{2}{|c|}{-0.54} & -0.42 & 5 \\
\hline Italy & \multicolumn{2}{|c|}{0.96} & 2.21 & 3 & \multicolumn{2}{|c|}{0.97} & 2.43 & 3 \\
\hline Lithuania & \multicolumn{2}{|c|}{1.18} & 1.18 & 4 & \multicolumn{2}{|c|}{1.26} & 1.18 & 4 \\
\hline Switzerland & \multicolumn{2}{|c|}{1.05} & 4.92 & 1 & \multicolumn{2}{|c|}{1.18} & 5.69 & 1 \\
\hline
\end{tabular}

As seen from Tables 4 and 5, the proposed methodology for the quantitative assessment of the dynamics of the SES economic development represents both the economic development of each country and its nature in an adequate manner. It is a universal solution and it may be applied for the assessment and analysis of the dynamics of any socioeconomic processes and phenomena.

\section{Conclusions}

A prerequisite for the existence of socioeconomic systems is their development; therefore, both from the scientific and the practical points of view, it is important to examine this process in a comprehensive manner and to look for the conditions affecting its success. In order to study the process of SES development, it must also be scrutinised in a quantitative manner.

The process of SES economic development is characterised by its dynamics, which in turn may be measured using two indicators: the intensity of the development and its consistency over the reference period. The intensity of the development may be represented as a ratio between the values of the economic development at the end and at the start of a given period.
The actual trajectory of the SES economic development over the reference period may be depicted using the hypotenuses of right-angled triangles that have been generated for every individual time period. One section of this triangle represents the scope of the economic development over the reference time period; whereas the other one represents the length of this time period. In such a case, the consistency of the SES economic development will be demonstrated by a ratio of the length of the reference period to the sum of the lengths of the sides of the triangle.

The dynamics of the SES development over the reference period are represented by the product of the indicators for its intensity and its consistency. However, there is an alternative approach to determine the intensity of these indicators for the dynamics of development. In this scenario, they are weighted and the indicators being sought for the dynamics of the development are obtained as a sum of the indicator weights and the product of their values.

The assessment of the dynamics of the economic development in the reference countries, carried out on the basis of the proposed methodology, has proved that it is appropriate. It is a universal solution and it may be applied for the assessment and analysis of the dynamics of any socioeconomic processes and phenomena.

\section{References}

Armas-Cruz, Y., Gil-Soto, E., \& Oreja-Rodriguez, J. R. (2017). Environmental management in SMEs: organizational and sectoral determinants in the context of an Outermost European Region. Journal of Business Economics and Management, 18(5), 935-953, https://doi.org/10.3846/16111699.2017.1373375.

Babu, S., \& Datta, S. K. (2015). Revisiting the link between socio-economic development and environmental status indicators - focus on panel data. Environment, Development and Sustainability 17(3), 67-586. http://dx.doi.org/10.10 07/ s10668-014-9561-6.

Boggia, A., \& Cortina, C. (2010). Measuring sustainable development using a multi-criteria model: A case study. Journal of Environmental Management, 91, 2301-2306. https://doi.org/10.1016/j.jenvman.2010.06.009

Bolcarova, P., \& Kolosta, S. (2015). Assessment of sustainable development in the EU 27 using aggregated SD index. Ecological Indicators 48, 699-705. http://dx.doi.org/10.1016/j.ecolind.2014.09.001.

Chansarn, S. (2013). Assessing the Sustainable Development of Thailand. Procedia Environmental Sciences 17, 611-619. http://dx.doi.org/10.1016/j.proenv.2013.02.077.

Ciegis, R., Ramanauskiene, J., \& Simanskiene, L. (2010). Lietuvos regionų darnaus vystymosi vertinimas. Klaipeda: Klaipedos universiteto leidykla. 123 p. ISBN 978-9955-18-534-5.

Dobrovic, J., Timkova, V. (2017). Examination of Factors Affecting the Implementation of Organizational Changes. Journal of Competitiveness, 9 (4), 5-7. https://doi.org/10.7441/joc.2017.04.01. 
Romualdas Ginevicius, Dainora Gedvilaite, Andrius Stasiukynas, Jolita Sliogeriene. Quantitative Assessment of the...

Docekalova, M., Kocmanova, A., \& Kolenak , J. (2015). Determination of Economic Indicators in the Context of Corporate Sustainability Performance. Business: Theory and Practice, 16(1), 15-24. https://doi.org/10.3846/btp.2015.450.

Eurostat. Available from internet: http://appsso.eurostat.ec.europa.eu/nui/show.do?dataset=nama_10_pc\&lang=en.

Ginevicius, R., Gedvilaite, D., \& Bruzge, S. (2015). Assessment of a country's regional economic development on the basis of Estimation of a Single Process (ESP) method. Entrepreneurial business and economics review (EBER), 3(2), 141153. https://doi.org/10.15678/EBER.2015.030210

Ginevicius, R., Gedvilaite, D., Stasiukynas, A. (2016). Complex Assessment of the Ecological Development of the Country's Regions. The 9th International Scientific Conference "Business and Management 2016", May 12-13, 2016, Vilnius, Lithuania. Vilnius: Technika, 2016. ISSN 2029-4441, p. 1-9. https://doi.org/10.3846/bm.2016.60

Hashem-Nazari, M., Esfahanipour, A., \& Fatemi Ghomi, S. M. T. (2017). Non-equidistant "Basic Form"-focused Grey Verhulst Models (NBFGVMs) for ill-structured socio-economic forecasting problems, Journal of Business Economics and Management, 18 (4,) 676-694, https://doi.org/10.3846/16111699.2017.1337045.

Hodinkova, M., \& Sadovsky, Z. (2016). The benefits of corporate social responsibility introduction in small and mediumsized enterprises: a systematic review of the literature. Business: Theory and Practice, 17(4), 345-352. https://doi.org/10.3846/btp.17.11130.

Hwang, C. L., \& Yoon, K. (1981). Multiple Attribute Decision Making: Methods and Applications. Springer-Verlag, New York. http://dx.doi.org/10.1007/978-3-642-48318-9.

Jia, Z., Haifeng, X., Jincheng, S., \& Xuelin, Z. (2007.) Assessment of Sustainable Development System in Suihua City, China. Chinese Geographical Science, 17(4), 304-310. http://dx.doi.org/10.1007/s11769-007-0304-6.

Lithuanian dictationary. Available from internet: http://www.lkz.lt/Visas.asp?zodis=dinamika\&lns=-1\&les=-1.

Mally, K. M. (2018). Regional Differences in Slovenia from the Viewpoint of Achieving Europe's Sustainable Development. Acta geographica Slovenica, 58 (2), 32-46. https://doi.org/10.3986/AGS.3309.

Mardani, A., Jusoh, A., Nor, K. M. D., Khalifah, Z., Zakwan, N., \& Valipour, A. (2015). Multiple criteria decision-making techniques and their applications - a review of the literature from 2000 to 2014. Economic Research-Ekonomska Istrazivanja, 28(1), 516-571. https://doi.org/10.1080/1331677X.2015.1075139

Radovanovic, M., \& Lior, M. (2017.) Sustainable economic-environmental planning in Southeast Europe - beyond-GDP and climate change emphases. Sustainable Development, 25, 580-594. http://dx.doi.org/10.1002/sd.1679.

Strakova, J. (2015) Sustainable Value Added as We Do Not Know It. Business: Theory and Practice 16(2), 168-173. https://doi.org/10.3846/btp.2015.453.

Strezov, V., Evans, A., \& Evans, T. J. (2017). Assessment of the Economic, Social and Environmental Dimensions of the Indicators for Sustainable Development. Sustainable Development, 25 (3), 242-253. https://doi.org/10.1002/sd.1649.

Touceda, M. I., Neila, F. J., \& Degrez, M. (2018). Modeling socioeconomic pathways to assess sustainability: a tailored development for housing retrofit. The International Journal of Life Cycle Assessment, 23 (3), $710-725$. https://doi.org/10.1007/s11367-016-1194-6.

Tvaronaviciene, M., \& Razminiene, K. (2017). Towards Competitive Regional Development Trough Clusters. Journal of Competitiveness, 9 (4), 33-147. https://doi.org/10.7441/joc.2017.04.09.

Wegner, D., Zarpelon, F. M., Verschoore, J. R., \& Balestrin, A. (2017) Management practices of small-firm networks and the performance of member firms. Business: Theory and Practice, 18(1), 197-207. https://doi.org/10.38 46/btp.2017.021.

Zavadskas, E. K., Turskis, Z., \& Kildiene, S. (2014). State of Art Surveys of Overviews on MCDM/MADM Methods. Technological and Economic Development of Economy, 20(1), 165-179. http://dx.doi.org/10.3846/2 0294913.2014.892037.

Zhou, J., Xiao, H., Shang, J., \& Zhang, X. (2007). Assessment of sustainable development system in Suihua City, China, Chinese. Geographical Science, 17(4): 304-310. https://doi.org/10.1007/s11769-007-0304-6

Zinatizadeh, S., Azmi, A., Monavari, S. M., \& Sobhanardakani, S. (2017). Evaluation and prediction of sustainability of urban areas: A case study for Kermanshah city, Iran. Cities, 66, 1-9. https://doi.org/10.1016/j.cities.2017.03.002.

The article has been reviewed.

Received in March, 2018; accepted in June, 2018. 